
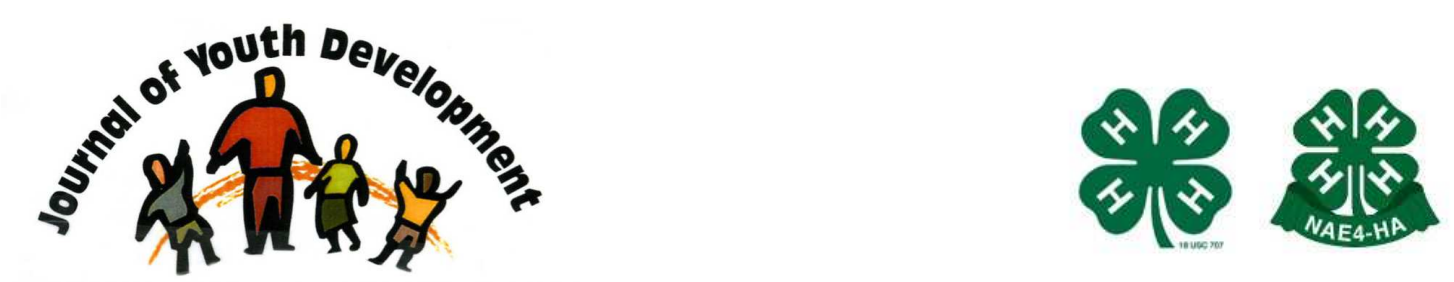

Bridging Research \& Practice

\title{
Explaining Research Utilization Among 4-H Faculty, Staff, and Volunteers: The Role of Self-Efficacy, Learning Goal Orientation, Training, and Previous Experience
}

\author{
Julianne Tillman \\ Department of Industrial/Organizational Psychology \\ Seattle Pacific University \\ Seattle, WA \\ juliab@spu.edu
}

Lynette H. Bikos

Department of Clinical Psychology

Seattle Pacific University

Seattle, WA

lhbikos@spu.edu 


\title{
JOURNAL OF YOUTH DEVELOPMENT \\ bridging research and practice

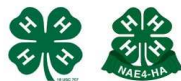

\section{Explaining Research Utilization Among 4-H Faculty, Staff, and Volunteers: The Role of Self-Efficacy, Learning Goal Orientation, Training, and Previous Experience}

\author{
Julianne Tillman and Lynette $\mathrm{H}$. Bikos \\ Seattle Pacific University
}

\begin{abstract}
An investigation of factors that facilitate the utilization of research evidence among faculty, staff, and volunteers in the 4- $\mathrm{H}$ Youth Development Program is presented in this paper. Participants ( $N=368 ; 86$ 4-H faculty, 153 staff, and 129 volunteers) represented 35 states; structural equation modeling was utilized in the analyses. Results of the path analysis explained $56 \%$ of variance in research utilization and $28 \%$ in research utilization selfefficacy. Among the factors impacting research utilization, selfefficacy played the most important role. In turn, self-efficacy for research utilization was positively influenced by participants' learning goal orientation, frequency of $4-\mathrm{H}$ training during the last 12 months, education in research-related areas, and investigative career interests. In addition, 4-H staff who were exposed to research at higher levels reported higher research utilization selfefficacy. The findings reinforce the importance of fostering research utilization self-efficacy among 4-H faculty, staff, and volunteers. Among the suggestions presented are regular $4-\mathrm{H}$ training opportunities and on-going exposure to program evaluation and program improvement experiences.
\end{abstract}

\section{Introduction}

The importance of evidence-based practice (EBP) continues to grow in both for-profit and not-forprofit sectors, impacting such diverse fields as medical practice and education. No matter the field, the success of any EBP depends on the practitioner's ability to find, select, and apply research and research-based evidence to his or her practice. Research utilization, thus, represents an integral part of EBP and is defined as the use of research to guide practice (Barwick, et al., 2008). Unfortunately, despite decades of investigations, modifications to training programs, and changes in policy, research is not being utilized to the desired extent (Tucker, Olson, \& Frusti, $2009 \mathrm{a} / \mathrm{b}$ ). The available findings are inconclusive, and there is little direction available to policy 
makers for creating conditions that allow the connections between research and practice to be made.

\section{Research utilization in $\mathbf{4 - H}$ is relevant}

EBP and research utilization also impact the 4-H Youth Development Organization. The ability to successfully utilize research-based programming around positive youth development has been at the core of 4-H for decades (4-H Youth Development Organization, n.d.). As part of the SmithLever Act of 1914, 4-H is expected to provide research-based knowledge from the College/ University to all US citizens cooperatively funded by federal, state, and local government funds. Despite such a strong focus on research-based information, a recent investigation by Bikos and colleagues (2011) indicated that 4- $\mathrm{H}$ faces the same struggles as do other organizations. Specifically, there is a gap between research and its utilization among 4- $\mathrm{H}$ faculty, staff, and volunteers. The goal of this project was to build on the findings by Bikos and colleagues and to further explore the factors that facilitate research use in the 4-H context. Specifically, our purpose was to propose and evaluate a model of research utilization for 4-H faculty, staff, and volunteers. Subsequently, we evaluated the relationships among the variables in the model to see if they differed for faculty, staff, and volunteers. In this introduction we briefly present the framework for this study, and in so doing, review research findings related to research utilization and self-efficacy for research utilization.

\section{Theoretical framework and literature review}

While primarily influenced by the social cognitive career theory ((SCCT); Betz, \& Hackett, 1986; Lent, Brown, \& Hackett, 1994) this study was also guided by the goal orientation theory (Dweck, 1986; Dweck, \& Leggett, 1988). Both theories represent a social-cognitive approach to motivation and, although independent, share some similarities.

Social cognitive career theory. Our study was grounded in SCCT (Betz \& Hackett, 1986; Lent, et al., 1994), a career-specific extension of social cognitive theory (Bandura, 1986). SCCT offers a framework for understanding career-specific development, explaining career interests, career choice, and career performance. While the SCCT model contains a number of variables (e.g., selfefficacy, contextual barriers and supports, interests, goals, and outcome expectations), selfefficacy is located at the center and serves as a strong and consistent predictor of actions (Lent, et al., 2003). Self-efficacy refers to the "beliefs in one's capability to recognize and execute courses of action required to manage prospective situations" (Bandura, 1997, p. 2). According to Bandura (2000), the belief in personal efficacy is the focal and pervading motivational mechanism that affects human functioning both directly and through its impact on other determinants. Selfefficacy impacts goals, effort, and persistence in the face of obstacles.

Researchers in various fields have explored both the impacts of situation specific self-efficacy (SSE; in our case research utilization self-efficacy [RUSE]) and general self-efficacy (GSE) on behavior. SSE is thought to be a state-like belief, serving as a robust predictor in specific situations, while GSE is considered to be a trait-like belief, predicting behavior across situations (Imam, 2007; Scherbaum, Cohen-Charash, \& Kern, 2006; Scholz, Gutiérrez-Doña, Sud, \& Schwarzer, 2002). Numerous researchers found SSE to be a good predictor of behavior, including contexts involving research utilization. For example, Bonetti and colleagues (2009) found that self-efficacy explained the use of evidence-based practice among dentists. Similarly, Godin, Belanger-Gravel, Eccles, and Grimshaw (2008) found that health care professionals' beliefs about their capabilities to implement research findings in their practice were the best predictors of both intention and actual implementation of research findings. On the other hand, findings regarding the predictive ability of GSE are mixed. While some researchers found that GSE can predict behavior as well as SSE 
(Becker, 2007), others reported that the impacts of GSE are fully mediated by SSE (Chen, Gully, Whiteman, \& Kilcullen, 2000). Consequently, we expected RUSE to have a strong direct relationship with research utilization. In addition, because of mixed findings, we expected GSE to be positively related to research utilization and to RUSE.

Given the importance of SSE, researchers have invested much to understand the factors that impact it. Several studies highlighted the importance of training and previous experience in shaping research self-efficacy. For example, Tucker and colleagues (2009a) showed an increase in self-efficacy among nurses who completed a program on evidence-based practice. Williams and Coles (2003) reported that teachers' confidence in utilizing research was related to their current or previous involvement in research. Consequently, we expected training, education, and previous exposure to research to be positively related to RUSE. On the other hand, given GSE's trait like qualities, we expected GSE to predict training and education.

In the SCCT model, career interests represent another important component and serve as indirect predictors of self-efficacy (Lent, et al., 2003). For example, in a study of research productivity among students, Bishop and Bieschke (1998) found that students' investigative career interests were a significant predictor of students' research self-efficacy. On the other hand, students' realistic interests were negatively related to research self-efficacy, and social interests were not related to research self-efficacy. Consequently, we expected investigative career interests to be positively related to RUSE, realistic interests to be negatively related to RUSE, and social interests to be unrelated to RUSE.

Goal orientation theory. Additionally, our study was shaped by goal orientation theory (Dweck, 1986; Dweck, \& Leggett, 1988), which also presents a social-cognitive approach to motivation. According to this theory, individuals who believe that traits are fixed tend to display maladaptive patterns, such as setting performance goals focused on obtaining positive judgments of individual competence. Individuals who believe that traits are malleable (e.g., intelligence can be developed) tend to display adaptive patterns such as setting learning goals focused on increasing competence in a given task. Individuals with this adaptive learning goal orientation (LGO) seek challenge and display persistence in the face of obstacles. Decades of research on goal orientation have shown that one's orientation is linked to a number of important outcomes, including performance and knowledge (Bell, \& Kozlowski, 2002). Performance goals lead to high performance on easy tasks but generally equivocal or negative performance on challenging activities, whereas learning goals usually lead to high performance regardless of task difficulty (Elliott, \& Dweck, 1988).

Although the concept of LGO developed parallel to the concept of self-efficacy, and the two constructs take somewhat different views on human motivation (LGO deals with individual inclinations toward specific kinds of experience, and self-efficacy is one's belief in being able to perform certain actions), they seem to be related; strong correlations, with raround .50, have been reported (e.g., McKinney, 2003). In addition, LGO has predicted performance beyond GSE (Chen, Gully, Whiteman, \& Kilcullen, 2000; Colquitt, \& Simmering, 1998). Given these findings, we expected LGO to have both a positive relationship to research utilization and a positive relationship to self-efficacy.

In educational settings, LGO seems to be positively related to motivation to learn (Klein, Noe, \& Wang, 2006) and to grades and test performance (Button, Mathieu, \& Zajac, 1996). People with a high LGO tend to be better at regulating their learning (Bouffard, Boisvert, Vezeau, \& Larouche, 1995); they are more likely to engage in thoughts and activities directed towards achieving new skills. LGO even plays an important role in the workplace, as older workers with high LGO tend to 
believe that age-related decline in learning ability can be controlled and, as a result, tend to be more likely to engage in developing career-relevant skills (Wrenn, \& Maurer, 2004). Consequently, we expected LGO to be positively related to training, education, and previous exposure to research.

\section{Research questions}

The purpose of our project was to examine the theoretical relationships among the aforementioned variables for 4-H faculty, staff, and volunteers and then evaluate if and how these relationships differ for each of the groups, separately. Drawing on earlier findings and the results reported by Bikos and colleagues (2011) and employing a social cognitive framework, we hypothesized the following (see Figure 1):

Hypothesis 1 - research utilization self-efficacy: (a) RUSE will be positively related to research utilization.

Hypothesis 2 - general self-efficacy: (a) GSE will be positively related to research utilization; (b) GSE will be positively related to RUSE; (c) GSE will be positively related to training and education.

Hypothesis 3 - learning goal orientation: (a) LGO will be positively related to research utilization; (b) LGO will be positively related to GSE and RUSE; (c) LGO will be positively related to training and education.

Hypothesis 4 - career interests: (a) investigative career interests will be positively related to RUSE; (b) investigative career interests will be positively related to education, training, and previous exposure to research; (c) realistic career interests will be negatively related to RUSE; (d) social career interests will not be related to RUSE.

Hypothesis 5 - other predictors of specific self-efficacy: (a) education, training, and previous exposure to research will be positively related to RUSE; (b) education will be positively related to previous exposure to research. 
Figure 1

Hypothesized relationships: + indicates a positive relationship, - indicates a negative relationship, 0 indicates no significant relationship. LGO - learning goal orientation; GSE general self-efficacy; RUSE - research utilization self-efficacy

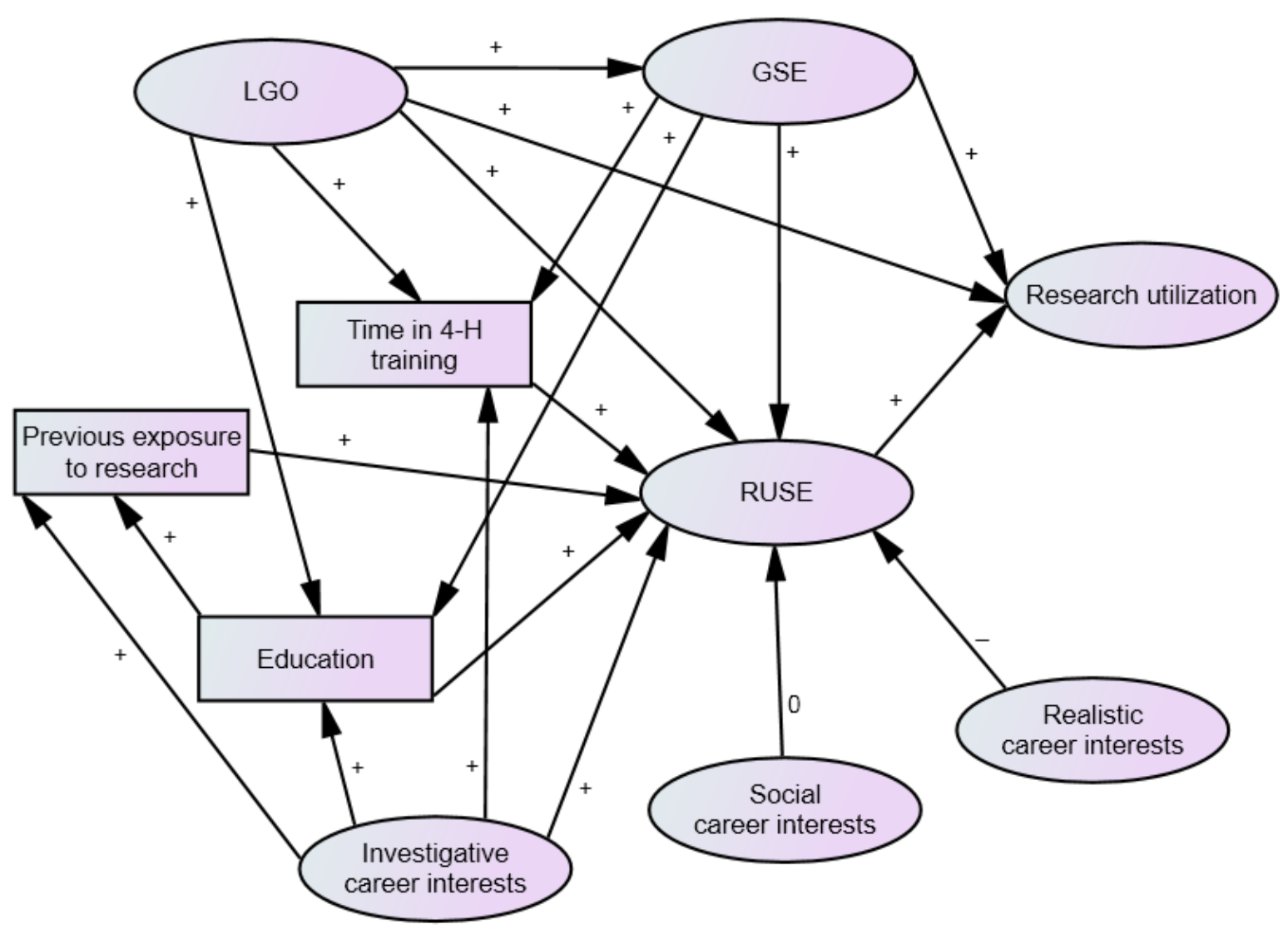

Method

\section{Participants}

More than 500 participants attempted to complete the survey; however, only 368 were included in the analyses due to drop out and missing data. Of these 368, 86 were 4-H faculty, 153 staff, and 129 volunteers. Participants were from 35 US states, with Georgia representing the largest percentage of the sample (10.1\%), followed by Illinois (7.7\%), and Missouri (6.8\%). Participant ages ranged from 21 to 74 years old $(M=44.64, S D=11.96)$; the majority were female $(84.0 \%)$ and White, Non-Hispanic (88.9\%). More than half of the participants were involved in $4-\mathrm{H}$ in their youth $(60.0 \%)$, and more than half volunteered with $4-\mathrm{H}$ at some point in their life $(68.2 \%)$. Most of the participants reported at least some involvement in $4-\mathrm{H}$ at the club level $(75.5 \%)$ and the county level (83.7\%). Fewer reported being involved at the state level $(60.3 \%)$, and even fewer were involved at the federal level (13.9\%).

\section{Sampling procedures}

Participants were recruited through multiple methods such as e-mailing 4-H faculty and staff listed on 4-H state and county websites; placing advertisement on 4-H websites, in 4-H publications, and at 4-H gatherings; and via snowballing. The survey was administered on-line, and participants were e-mailed an invitation to participate in the study with a link to the on-line survey. 


\section{Measures}

Training and education. Education, research experience, and 4-H training information was gathered using author-created scale. The education question asked about the nature of involvement in research and program evaluation related areas; the involvement ranged from "no training" to "training as part of a graduate degree." The responses were averaged to obtain the average education. Previous research experience was assessed by asking about the research activities involved in during the last five years ranging from responding to survey questions to leading a scientific research project. The responses were coded to determine (a) the diversity of involvement (i.e., in how many different activities the respondent participated) and (b) the level of involvement (the lowest level included being simply a study participant, and the highest level was leading a research project). There were two training questions asking "How often do you attend 4-H or extension training (or other training that assists you with your 4-H work) per year?" and "During the last 3 years, how many hours did you spend in these 4-H related trainings (please provide your best estimate)?"

Research utilization and self-efficacy for research utilization. Both research utilization and research utilization self-efficacy were assessed with author-constructed scales. The questions were based on the findings by Bikos and colleagues (2011) and were reviewed by a small group of 4-H faculty, staff, and volunteers. After the scales were modified based on the stakeholders' feedback, they were subjected to an extensive psychometric evaluation as the primary focus of the first author's doctoral dissertation (Tillmann, 2013). The scales have a parallel structure and are composed of three factors: (a) research integration, (b) research production, and (c) research acquisition (utilizing scholarly sources, events and experts, and 4-H sources).

The research utilization scale measures the extent to which a respondent uses research-based information in carrying out his/her 4-H responsibilities and asks about the type of resources used to obtain that information. The scale consists of 21 questions, measured on a scale of 0 (never) to 10 (all of the time). One section of the scale asks, "How often do you use the following sources to obtain the information needed to perform your 4-H work/responsibilities?" Some of the sources listed include research-specific search engines, trainings, and 4- $\mathrm{H}$ materials/curriculum. The second section asks "How often do you perform the following?" Some of the activities listed include "performing evaluations/reviews after 4-H activities and events" and "incorporating the results of evaluations/reviews into future 4-H activities and events." The third section inquires about the use of research-based information when carrying out certain 4-H activities; some of these activities include determining how to best work with leaders and volunteers, training leaders and volunteers, and developing program materials. In an initial evaluation (Tillmann, 2013), the scale displayed good internal consistency; the total scale alpha coefficient in this study was .942. A total scale score can be obtained by averaging all of the items; alternatively, average scores can be obtained for each factor. Higher scores indicate higher research utilization.

The research utilization self-efficacy scale (RUSE) consists of 18 questions, measured on a scale of 0 (not at all confident) to 10 (completely confident). The scale asks the respondent to rate his/her level of confidence in (a) utilizing research-based information when performing certain 4-H activities such as planning programs, developing program materials, and training leaders and volunteers; (b) using certain resources when searching for research-based information, such as research-specific search engines, search engines hosted by libraries or professional associations, and 4-H materials/curriculum; and (c) producing and using information derived from program evaluation. In an initial evaluation (Tillmann, 2013), the scale displayed good internal consistency reliability; the total sale alpha in this study was .937. A total scale score can be obtained by 
averaging all of the items; alternatively, average scores can be obtained for each factor. Higher scores indicate higher research utilization self-efficacy.

General self-efficacy. The new general self-efficacy scale was used to measure GSE (Chen, Gully, \& Eden, 2001). The scale is a brief measure that contains 8 items, rated on a scale of 1 (strongly disagree) to 5 (strongly agree); higher scores indicate higher self-efficacy. Sample items include "I will be able to achieve most of the goals that I have set for myself" and "Compared to other people, I can do most tasks very well." The reliability of the scale is strong, with alpha coefficients ranging from .85 to .90; in this study, Cronbach's alpha was .906. The scale's testretest reliability, assessed at a 20-day interval, was $r=.67$ (Chen, Gully, \& Eden, 2001). When compared to other GSE scales, the new general self-efficacy scale performed just as well as the similar scales; yet, it is shorter (Scherbaum, et al., 2006).

Learning goal orientation. LGO was assessed using the learning goal orientation subscale of the goal orientation scale (Button, et al., 1996). The subscale consists of 8 items rated on a scale of 1 (strongly disagree) to 7 (strongly agree); higher scores indicate stronger LGO. Sample questions include "I do my best when I'm working on a fairly difficult task" and "The opportunity to learn new things is important to me." The reliability coefficients range from .77 (Bell, \& Kozlowski, 2002) to .87 (Hafsteinsson, Donovan, \& Breland, 2007); in our study, Cronbach's alpha was .911. The validity of the scale has been supported by its positive relationship with self-esteem $(r=.480)$ and work locus of control $(r=.901$; Button, et al., 1996), and GSE $(\beta=.24)$ and performance $(\beta$ $=.14$; Bell, \& Kozlowski, 2002).

Career interests. To measure participant's investigative, realistic, and social career interests, we used the brief public domain, activity-based, RIASEC marker scale, Activities - Set A, developed by Armstrong, Allison, and Rounds (2008). This scale contains 48 items and includes all 6 of Holland's (1959; 1997) career interests categories: realistic, investigative, artistic, social, enterprising, and conventional. Each category contains 8 items, rated on a 1 (strongly dislike) to 5 (strongly like) scale, and can be administered separately or in combination with any or all of the other categories. The scores are computed by summing the responses for each category. Sample activities include study animal behavior (for investigative interests), install flooring in houses (for realistic interests), and teach children how to read (for social interests). In an initial investigation by Armstrong and colleagues (2008), the scale had good internal consistency reliability. The reliability coefficients for investigative interests ranged from .89 to .91 (.90 in this study), realistic interests from .82 to .90 (.86 in this study), and social interests from .80 to .91 (.75 in this study).

\section{Results}

\section{Preliminary analyses}

First, the dataset was analyzed for missing data. Cases with more than $24 \%$ of missing data were removed; multiple imputation (Enders, 2010) was used to estimate missing data in the remaining cases $(N=368)$. Next, the data was screened for outliers and multivariate normality. One case stood out as an outlier. Upon closer examination, it was determined that this participant had spent considerably more time in 4-H related training during the last three years than any of the other participants. However, this case was representative of an important segment of the 4-H organization and was included in the subsequent analyses. In examining the multivariate normality, we found two items to be non-normally distributed: 4-H related training hours completed during the last 3 years and number of times 4-H training was attended during the past year. Given that there are ingrained organizational differences in training type and frequency (e.g., 4-H staff is expected to attend 4- $\mathrm{H}$ training on a regular basis while volunteers are only encouraged to do so), the items were left as is, and the skew was taken into consideration during 
analysis interpretation. Once the dataset was defined, preliminary analyses were carried out. Specifically, we calculated means and standard deviations for the variables and bivariate correlations (see Table 1).

Table 1

Correlations and Means

\begin{tabular}{|c|c|c|c|c|c|c|c|c|c|c|c|c|}
\hline Variable (Mean, SD) & 1 & 2 & 3 & 4 & 5 & 6 & 7 & 8 & 9 & 10 & 11 & 12 \\
\hline $\begin{array}{l}\text { 1. RUSE } \\
(8.46,1.65)\end{array}$ & 1 & & & & & & & & & & & \\
\hline 2. Research utilization & 0.72 & 1 & & & & & & & & & & \\
\hline$(7.23,2.07)$ & $* *$ & & & & & & & & & & & \\
\hline 3. GSE & 0.33 & 0.26 & 1 & & & & & & & & & \\
\hline$(4.34,0.52)$ & $* *$ & $* *$ & & & & & & & & & & \\
\hline 4. LGO & 0.39 & 0.35 & 0.63 & 1 & & & & & & & & \\
\hline$(6.01,0.78)$ & $* *$ & $* *$ & $* *$ & & & & & & & & & \\
\hline 5. Training - 12 months & 0.23 & 0.24 & 0.04 & 0.06 & 1 & & & & & & & \\
\hline$(4.84,6.57)$ & $* *$ & $* *$ & & & & & & & & & & \\
\hline 6. Training - 3 years & 0.09 & 0.07 & -0.02 & -0.05 & 0.16 & 1 & & & & & & \\
\hline$(120.12,365.48)$ & & & & & $* *$ & & & & & & & \\
\hline $\begin{array}{l}\text { 7. Prev. research } \\
\text { diversity }\end{array}$ & 0.20 & 0.18 & 0.11 & 0.12 & 0.13 & 0.11 & 1 & & & & & \\
\hline$(1.83,1.32)$ & $* *$ & $* *$ & $*$ & $*$ & $*$ & $*$ & & & & & & \\
\hline 8. Prev. research level & 0.25 & 0.22 & 0.12 & 0.09 & 0.11 & 0.10 & 0.85 & 1 & & & & \\
\hline$(2.34,1.53)$ & $* *$ & $* *$ & * & & * & * & $* *$ & & & & & \\
\hline 9. Avg. education & 0.30 & 0.21 & 0.07 & 0.17 & 0.10 & 0.05 & 0.53 & 0.52 & 1 & & & \\
\hline$(2.17,1.52)$ & $* *$ & $* *$ & & $* *$ & * & & $* *$ & $* *$ & & & & \\
\hline 10. Realistic interests & 0.11 & 0.10 & 0.02 & 0.10 & 0.02 & 0.00 & -0.03 & -0.04 & -0.05 & 1 & & \\
\hline$(18.63,6.16)$ & $*$ & & & & & & & & & & & \\
\hline $\begin{array}{l}\text { 11. Investigative } \\
\text { interests }\end{array}$ & 0.07 & 0.07 & 0.12 & 0.16 & 0.04 & -0.03 & 0.21 & 0.22 & 0.19 & 0.33 & 1 & \\
\hline$(25.67,7.56)$ & & & $*$ & $* *$ & & & $* *$ & ** & $* *$ & $* *$ & & \\
\hline 12. Social interests & 0.16 & 0.19 & 0.19 & 0.20 & 0.07 & 0.03 & 0.04 & 0.07 & 0.06 & 0.19 & 0.26 & 1 \\
\hline$(30.44,4.77)$ & $* *$ & $* *$ & $* *$ & $* *$ & & & & & & $* *$ & $* *$ & \\
\hline
\end{tabular}

\section{Primary analyses}

Our primary analyses occurred in stages. First, using structural equation modeling in AMOS 20, we evaluated the a priori hypothesized model (Figure 1). Specifically, we were interested in knowing if the strength and direction of the paths were consistent with our hypotheses. Additionally, we sought a model that fit well. In evaluating the model fit, we relied on three fit indices (Byrne, 2010): $\chi^{2}$ likelihood ratio statistic, the normed fit index (NFI), the comparative fit index (CFI), and the root mean square error of approximation (RMSEA). The goal is to have a non-significant $\chi^{2}$ value, which indicates that variances and covariances of the hypothesized model do not differ significantly from those in the data set. NFI compares the hypothesized model with the independence model (in which none of the variables are correlated) and produces fit values 
ranging from 0 to 1.00; higher values indicate better fit. CFI is a revised version of NFI and considers sample size, providing a better estimate in small samples. For both CFI and NFI a value of .95 indicates good fit. Finally, the RMSEA takes into account the error of approximation in the population and is sensitive to the complexity of the model. RMSEA values of .06 or less indicate good fit; the reasonable fit is represented by values ranging from .06 to .08 and the mediocre fit by values ranging from .08 to .1; values greater than .1 are indicative of poor fit.

Our initially hypothesized model displayed an unsatisfactory fit, $\chi^{2}(277, N=368)=954.645, p>$ $.01 ; \mathrm{NFI}=.866, \mathrm{CFI}=.900$, and RMSEA $=.082$. This a priori model accounted for $35.2 \%$ of variance in RUSE and $58.2 \%$ of variance in research utilization.

To derive a better fitting model, we employed a model trimming approach (Kline, 2005). Model trimming involves re-specifying the model as just-identified (i.e., with all possible paths and no degrees of freedom) and eliminating each non-significant regression weight, one at a time, on the basis of the largest associated $p$ value. This process aims to identify any previously unspecified significant paths and to trim non-significant paths. In addition, we examined the modification indices to determine if any covariances should be added. The ultimate goal of the model trimming approach is to produce a model that is theoretically meaningful, statistically well-fitting, and parsimonious (Byrne, 2010; Kline, 2005). The final model (Figure 2) displayed a good fit ( $\chi^{2}$ [95; $N=368]=181.868, p<.01, \mathrm{NFI}=0.963 \mathrm{CFI}=0.982$, and RMSEA $=0.050)$. This model accounted for $28 \%$ of variance in RUSE and $56 \%$ in research utilization. 
Figure 2

Re-Specified Model

The re-specified model with standardized path coefficients $\left(\chi^{2}[95 ; N=368]=181.868\right.$, $p<.01, \mathrm{NFI}=0.963 \mathrm{CFI}=0.982$, and RMSEA $=0.050$ ). All paths are significant at $p<.05$. Path coefficients are preceded by a positive or negative sign. The proportion of variance accounted for in the endogenous variables (e.g., those with arrows pointing to them) do not include +/notation. For example, the " $56 \%$ " above the research utilization variable indicates that $56 \%$ of the variance in research utilization is accounted for by the structural model that precedes it.

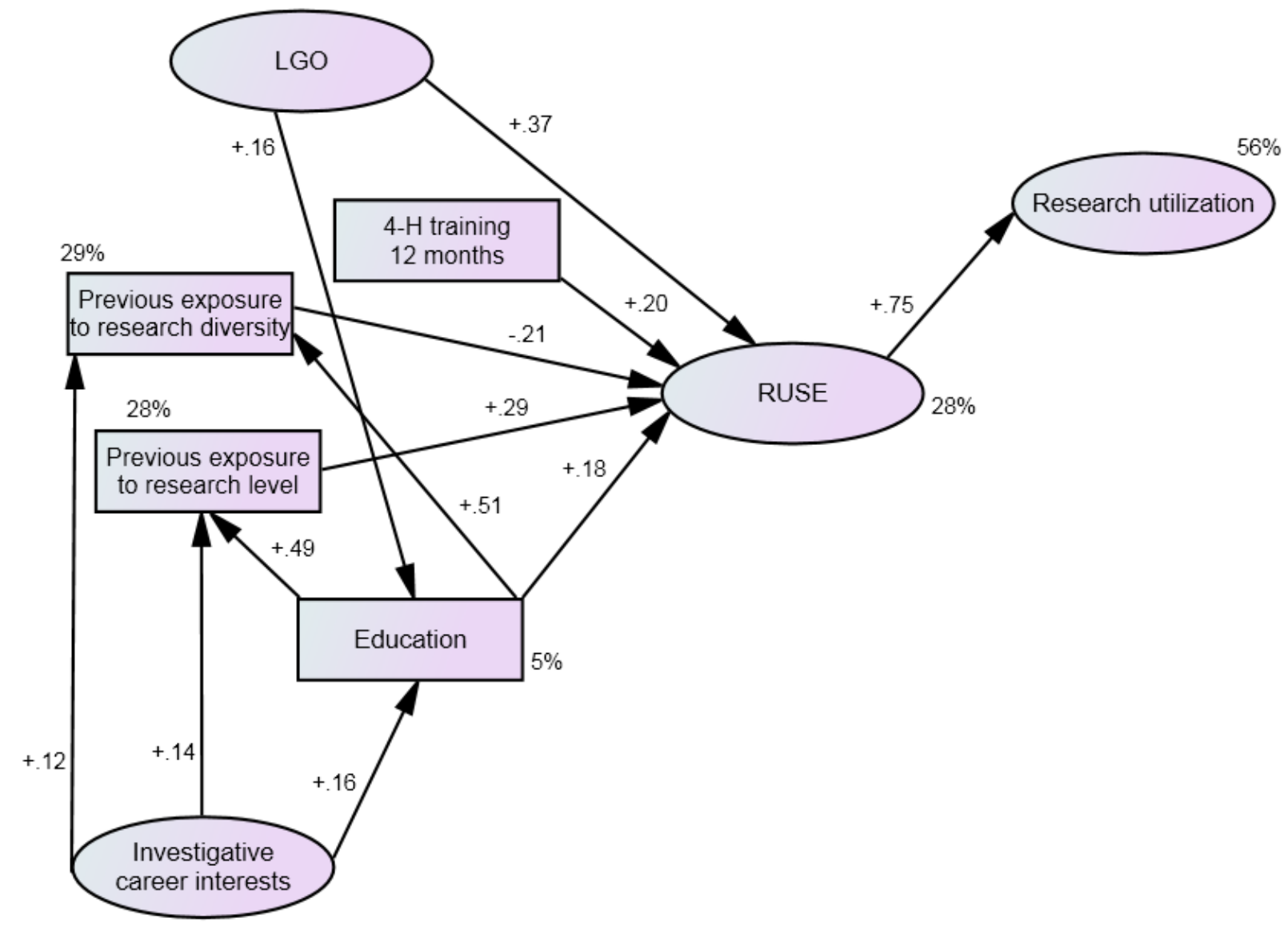

RUSE - research utilization self-efficacy, RU - research utilization, LGO - learning goal orientation.

\section{Group comparison}

Considering the underlying theoretical differences among the three groups of interest (staff, faculty, and volunteers), we carried out invariance testing on the final model across these groups. The goal of this procedure is to establish if and how the model differs among the three groups (Byrne, 2010). The examination of the paths indicated partial group invariance in the importance of previous research experience level. That is, previous research experience level had no relationship to RUSE among faculty $(\beta=-.108, p>.05)$ and volunteers $(\beta=.300, p>.05)$, but it was positively related to RUSE among staff $(\beta=.331, p<.01)$. 


\section{Discussion}

The goal of this project was to build on the findings by Bikos and colleagues (2011) and to further explore the factors that facilitate research use in the 4-H context. Similarly to Bikos and colleagues, we found that participants varied in their use of research-based information and in their confidence in using that information.

As hypothesized, RUSE was a strong predictor of research utilization among 4-H faculty, staff, and volunteers. In turn, LGO was a strong predictor of RUSE, and it had an indirect positive relationship to research use. The frequency of participation in the 4-H training and average education were also positive predictors of RUSE. In addition, as expected, social career interests were not related to RUSE.

The findings regarding previous research experience level were mixed. Specifically, the level of previous research experience was a significant predictor of RUSE among 4-H staff but not among faculty or volunteers. That is, 4- $\mathrm{H}$ staff who had an opportunity to be a research coinvestigator or who led a research project had higher self-efficacy than 4-H staff who simply participated in research or helped out with data collection. On the other hand, research experience level was not a significant predictor of self-efficacy among volunteers and faculty. This finding could be explained by low variability in these two groups; while faculty tend to be actively involved in research at higher levels, volunteers report a much lower level of involvement.

Contrary to our expectations, GSE did not predict research utilization or RUSE. In addition, we were surprised to find that previous research experience diversity was negatively related to RUSE. That is, being involved in research-related activities in various roles was linked to decreased RUSE. Finally, contrary to our expectations, realistic career interests were not significantly related to RUSE.

\section{Limitations}

The first limitation of this study is the sample. With this study being based on voluntary participation, the self-selection bias is clearly present. Furthermore, while faculty and staff were recruited across the country due to an easily available database of e-mail addresses, volunteers represent just a few states and were recruited through a snowball technique. Volunteers were also more likely to drop out of the survey early on, exacerbating the impacts of self-selection.

The second limitation is the exploratory nature of the model generating approach (Jöreskog, 1993). While the results provided support for most of the hypotheses, not all theorized paths were significant and not all of the regression weights and correlations for those retained were strong. Consequently, this study likely capitalized on sample-specific characteristics.

Finally, the results of the invariance testing should be interpreted with caution. First, the three groups were uneven in numbers ( 86 were 4-H faculty, 153 staff, and 129 volunteers). Second, the faculty group was not large enough to power the analyses. Consequently, the models generated for each group may be unstable, requiring further investigation.

\section{Practical implications}

This study is the first attempt at measuring and understanding the factors that impact RUSE and research use by 4-H faculty, staff and volunteers. Still, the results shed light on potential actions that the 4-H organization can take to maximize RUSE, thus increasing research use 
among 4-H faculty, staff, and volunteers. First, given that LGO is strongly and positively related to RUSE, it would be beneficial for the organization to foster learning orientation among its faculty, staff, and volunteers. Earlier studies (e.g., Elliott, \& Dweck, 1988; Martocchio, \& Hertenstein, 2003) showed that LGO can be fostered through suggestions before or during training. For example, in the study by Martocchio and Hertenstein, the researchers set up training modules to be either performance or learning oriented. In a performance oriented group, they used the following suggestions, "Focus on performing these exercises well by minimizing the mistakes you make. The fewer mistakes you make, the better you can use the Microsoft Access 97 program" (p. 422). In a learning oriented group, they used the following suggestions, "Learning how to use Microsoft Access 97 is developed through persistence and hard work. The old saying 'Practice makes perfect' holds true for computer skills. You will probably make mistakes. That's normal. People who learn how to use Microsoft Access 97 do not begin with faultless performance. Again, it is important to remember that the more practice you have, the more capable you will become" (p. 422). The suggestions were repeated throughout the course. Given that the 4-H organization provides ample training to its faculty, staff, and volunteers, the training could serve as a great opportunity to foster LGO among those present by using learning-oriented suggestions such as those used by Martocchio and Hertenstein.

Second, we found that training frequency during the past 12 months was positively related to RUSE. Based on this finding, we suggest that the 4-H organization should continue to offer regular training to 4- $\mathrm{H}$ faculty, staff, and volunteers. In addition, training attendance should be encouraged and incentivized to make sure that training opportunities are well utilized. The training can also be targeted using the results from the RUSE scale. Different segments in the organization could have less self-efficacy in some areas, and providing training that focuses on these areas could maximize the impact of training.

Finally, we would recommend 4-H staff to gain more practical experience of research through participating in program evaluation and program improvement. In addition, if an opportunity presents itself, it could be beneficial for 4-H staff to obtain research experience at higher levels by either collaborating on or leading a research project. It is important, however, to keep in mind that in this study the diversity of research-related involvement (i.e., in how many different activities the respondent participated) was negatively related to self-efficacy. Consequently, it may be beneficial to limit the diversity of such exposure.

\section{Next Steps}

This project represents the second step in a series of evaluations that we plan to carry out. In order to fully utilize the SCCT theory, we need to create two more scales (research utilization outcome expectations scale and barriers and facilitators of research use), and we need to further validate and improve the scales we create. In addition, given the complex nature of research utilization, we will continue to explore the factors that facilitate research use among 4$\mathrm{H}$ faculty, staff, and volunteers.

\section{References}

4-H Youth Development Organization. (n.d.). Retrieved from http://www.4-h.org/about/4-hhistory/.

Armstrong, P.I., Allison, W., \& Rounds, J. (2008). Development and initial validation of brief public domain RIASEC marker scales. Journal of Vocational Behavior, 73, 287-299. doi:

10.1016/j.jvb.2008.06.003. 
Bandura, A. (1986). Social foundations of thought and action: A social cognitive theory. Englewood Cliffs, NJ: Prentice-Hall.

Bandura, A. (1997). Self-efficacy: The exercise of control. New York: Freeman.

Bandura, A. (2000). Cultivate self-efficacy for personal and organizational effectiveness. In E.A. Locke (Ed.), Handbook of Principles of Organizational Behavior. Oxford, UK: Blackwell.

Barwick, M.A., Boydell, K.M., Stasiulis, E., Ferguson, H.B., Blase, K., \& Fixsen, D. (2008). Research utilization among children's mental health providers. Implementation Science, 3:19. doi: 10.1186/1748-5908-3-19.

Becker, S.P. (2007). Generalized perceived self-efficacy as a predictor of student success in a for-profit career college. Dissertation \& Theses Collection. Paper AAI3270292. Retrieved from Johnson \& Wales University site: http://scholarsarchive.jwu.edu/dissertations/AAI3270292.

Bell, B.S., \& Kozlowski, S.W.J. (2002). Goal orientation and ability: Interactive effects on selfefficacy, performance, and knowledge. Journal of Applied Psychology, 8オ3), 497-505. doi: 10.1037/0021-9010.87.3.497.

Betz, N.E., \& Hackett, G. (1986). Applications of self-efficacy theory to understanding career choice behavior. Journal of Social \& Clinical Psychology, 43, 279-289.

Bikos, L.H., Kocheleva, J.A., Campbell, T., Daryani, R., Chahil, S., Brown, T., Winberg, Y., \& Pavese, L. (2011). Investigating the utilization of research evidence in the 4-H Youth Development Program. Journal of Youth Development: Bridging research and practice, 6(2), article 110602FA002. Retrieved from http://data.memberclicks.com/site/nae4a/JYDfinal0602.pdf.

Bishop, R.M., \& Bieschke, K.J. (1998). Applying Social Cognitive Theory to interest in research among counseling psychology doctoral students: A path analysis. Journal of Counseling Psychology, 45(2), 182-188.

Bonetti, D., Johnston, M., Pitts, N.B., Deery, C., Ricketts, L., Tilley, C., \& Clarkson, J.E. (2009). Knowledge may not be the best target for strategies to influence evidence-based practice: Using psychological models to understand RCT effects. International Journal of Behavioral Medicine, 16, 287-293. doi: 10.1007/s12529-008-9017-1.

Bouffard, T., Boisvert, J., Vezeau, C., \& Larouche, C. (1995). The impact of goal orientation on self-regulation and performance among college students. British Journal of Educational Psychology, 65(3), 317-329. doi: 10.1111/j.2044-8279.1995.tb01152.x.

Button, S.B., Mathieu, J.E., \& Zajac, D.M. (1996). Goal orientation in organizational research: A conceptual and empirical foundation. Organizational Behavior and Human Decision Processes, $6 \pi 1), 26-48$.

Byrne, B.M. (2010). Structural equation modeling with AMOS: Basic concepts, applications, and programming $\left(2^{\text {nd }}\right.$ ed. $)$. New York: Routledge.

Chen, G., Gully, S.M., \& Eden, D. (2001). Validation of a new general self-efficacy scale. Organizational Research Methods, 4(1), 62-83. 
Chen, G., Gully, S.M., Whiteman, J-A., \& Kilcullen, R.N. (2000). Examination of relationships among trait-like individual differences, state-like individual differences, and learning performance. Journal of Applied Psychology, 85(6), 835-847. doi: 10.1037//OQ219010.85.6.835.

Colquitt, J.A., \& Simmering, M.I. (1998). Conscientiousness, goal orientation, and motivation to learn during the learning process: A longitudinal study. Journal of Applied Psychology, 83(4), 654-665.

Dweck, C. (1986). Motivational processes affecting learning. American Psychologist, 41(10), 1040-1048.

Dweck, C.S., \& Leggett, E.L. (1988). A social-cognitive approach to motivation and personality. Psychological Review, 95(2), 256-273.

Elliott, E.S., \& Dweck, C.S. (1988). Goals: An approach to motivation and achievement. Journal of Personality and Social Psychology, 54(1), 5-12.

Enders, C.K. (2010). Applied missing data analysis. T.D. Little, (Ed.). New York: The Guilford Press.

Godin, G., Belanger-Gravel, A., Eccles, M., \& Grimshaw, J. (2008). Healthcare professionals' intentions and behaviours: A systematic review of studies based on social cognitive theories. Implementation Science, 3:36. doi: 10.1186/1748-5908-3-36.

Hafsteinsson, L.G., Donovan, J.J., \& Breland, B.T. (2007). An item response theory examination of two popular goal orientation measures. Educational and Psychological Measurement, 674), 719-739. doi: 10.1177/0013164406299101.

Holland, J.L. (1959). A theory of vocational choice. Journal of Counseling Psychology, 6, 35-45.

Holland, J.L. (1997). Making vocational choices (3rd ed.). Odessa, FL: Psychological Assessment Resources.

Imam, S.S. (May 2007). Proceedings from the Redesigning Pedagogy: Culture, Knowledge and Understanding Conference. Singapore.

Jöreskog, K.G. (1993). Testing structural equation models. In K.A. Bollen \& J.S. Long (Eds.), Testing structural equation models (pp. 294-316). Newbury Park, CA: Sage.

Klein, H.J., Noe, R.A., \& Wang, C. (2006). Motivation to learn and course outcomes: The impact of delivery mode, learning goal orientation, and perceived barriers and enablers. Personnel Psychology, 59, 665-702. doi: 10.1111/j.1744-6570.2006.00050.x.

Kline, R.B. (2005). Principles and practice of structural equation modeling ( $2^{\text {nd }}$ ed.). New York: The Guilford Press.

Lent, R.W., Brown, S.D., \& Hackett, G. (1994). Toward a unifying Social Cognitive Theory of career and academic interest, choice, and performance. Journal of Vocational Behavior, 45, 79122.

Lent, R.W., Brown, S.D., Schmidt, J., Brenner, H.L., Lyons, H., \& Treistman, D. (2003). Relation of contextual supports and barriers to choice behavior in engineering majors: Test of alternative 
social cognitive models. Journal of Counseling Psychology, 58, 458-465. doi: 10.1037/00220167.50.4.458.

Martocchio, J.J., \& Hertenstein, E.J. (2003). Learning goal orientation and goal orientation context: Relationships with cognitive and affective learning outcomes. Human Resource Development Quarterly, 14(4), 413-434.

McKinney, A.P. (2003). Goal orientation: A test of competing models. (Doctoral dissertation). Retrieved from Virginia Tech Digital Library and Archives: http://scholar.lib.vt.edu/theses/available/etd-12082003110313/unrestricted/GoalOrientation AtestofCompetingModels.pdf.

Scherbaum, C.A., Cohen-Charash, Y., Kern, M.J. (2006). Measuring general self-efficacy: A comparison of three measures using item response theory. Educational and Psychological Measurement, 66(6), 1047-1063. doi: 10.1177/0013164406288171.

Scholz, U., Gutiérrez-Doña, B., Sud, S., \& Schwarzer, R. (2002). Is general self-efficacy a universal construct? Psychometric findings from 25 countries. European Journal of Psychological Assessment, 18(3), 242-251.

Tillmann, J. (2013). Creation and Validation of the 4-H Research Utilization Self-Efficacy Scale. (Unpublished doctoral dissertation). Seattle Pacific University, Seattle, WA.

Tucker, S.J., Olson, M.., \& Frusti, D.K. (2009a). Evidence-based practice self-efficacy scale: Preliminary reliability and validity. Clinical Nurse Specialist, 23(4), 207-215.

Tucker, S.J., Olson, M.E., \& Frusti, D.K. (2009b). Validity and reliability of the evidence-based practice self-efficacy scale. Western Journal of Nursing Research, 31(8), 1090-1091. doi: $10.1177 / 0193945909342552$.

Williams, D., \& Coles, L. (2003). The use of research by teachers: Information literacy, access and attitudes. Retrieved from http://www4.rgu.ac.uk/files/ACF2B02.pdf.

Wrenn, K.A., \& Maurer, T.J. (2004). Beliefs about older workers' learning and development behavior in relation to beliefs about malleability of skills, age-related decline, and control. Journal of Applied Social Psychology, 34(2), 223-242. doi: 10.1111/j.15591816.2004.tb02546.x.

(C) Copyright of Journal of Youth Development Bridging Research and Practice. Content may not be copied or emailed to multiple sites or posted to a listserv without copyright holder's express written permission. Contact Editor at: patricia.dawson@oregonstate.edu for details. However, users may print, download or email articles for individual use.

ISSN 2325-4009 (Print); ISSN 2325-4017 (Online) 